ing was "that with an accumulation of $\mathrm{CO}$, in the blood (blood from carotid artery in dyspnca) and in an amount not resulting in death, the deleterious effects of $\mathrm{KClO}_{3}$ are increased in great degree" (i. e., absorption bands of methemoglobin were noted after a much shorter space of time than with normal blood from the carotid). The same result was observed after addition of small amounts of acid sodium phosphate to blood.

My own conclusions are just contrary to the above where slight, therapeutic methemoglobinemia is concerned, and which may, therefore, be stated thus-in dyspneic conditions, the greater the rapidity of an induced methemoglobinemia proportionate to the needed oxidation of increased amounts of reducing substances in the blood, the greater and more rapid the benefit to the patient. This is also in accord with personal clinical experience as regards relief of dyspnea by administration of certain metriemoglobin-producing drugs in small amounts. I have not tested the effect of this same class of drugs in phosphorus poisoning, but I find in von Mehring's thesis the following reference: "Tessliers" observed at the clinic of du Aloulin in Gilent a case of phosphorus poisoning, wherein the patient, owing to great repugnance to turpentine, was given potassium chlorate, with apparent beneficial resuits." It is significant that turpentine shares with potassium chlorate methemoglobin producing properties. ${ }^{15}$

\section{SYMPTOMS, DIAGNOSIS AND PROGNOSIS OF UNCOMPLICATED INTESTINAL AMEBIA- SIS IN THE TROPICS.}

\author{
W. E. MUSGRAVE, M.D. \\ Iathologist, Government Laboratory; Physician in Chief, \\ St. Paul's Hospital. \\ MANILA, P. I.
}

\section{SYMPTOMATOLOGY}

The symptomatology of amebiasis varies more than is generally taught and it seems desirable that this more comprehensive clinical picture be taken up more in detail, calling particular attention to the early diagnosis of the disease and to some of the peculiarities of the milder forms.

In discussing this question, writers have generally divided the cases into groups according to the clinical manifestation which, as clinical conveniences, answer the purpose and are fairly uniform. Osler considers it under the headings acute and chronic. Harris divided the disease into very mild forms, moderately severe cases and very severe ones. Iafleur and Futcher divide them into grave and gangrenous forms, those of moderate intensity and chronic ones.

I shall discuss the subject under the following conrenient clinical divisions:

1. Tatent and masked infections.

2. Mild and moderately severe ones.

3. Severe cases, including gangrenous and diphtheritic ones.

\section{Infection in children and in the aged.}

14. Annal de la Soc. de med. de Gand, 1882 .

15. Other authorlties whlch may be referred to are: Beilsteln, F., Organische Chemie, Dritte Auflage. DaCosta, John C., Jr., Clinical Hematology, 1901. Ewing, James: Clinical Pathology of the Blood, 1903. Grawitz, Ernst: Klinische Pathologle des Blutes, 1896.

Kobert, Rudolf: Lehrbuch der Intoxicationen, 2 vol., 1902-1904; I. S. Dispensatory, 17th edition, Article on Ptomalnes, 1898. Wood, H. C., Therapeutics, Principles and Practice, 10th edition, 1897 .

H. Read in the Section on Practice of Medicine of the American Medical Association, at the Fifty-sixth Annual Session, July, 1905. Notr.-The other papers in this symposium wlll appear in a later issue of THE TOURNAL.
'These clinical forms often change from one to the other and may do so several times during the course of the disease in the same patient. The amebic process in all is essentially chronic, but acute symptoms from concurrent or secondary infection by other agents are frequently seen.

Latent Infections.-By this term are designated those cases in which there is a true pathologic process, containing amebas without diarrhea or other symptoms which would ordinarily indicate the presence of such an infection. ${ }^{x}$

It might be objected that this latency is really a period of incubation. In a sense, this may be true, but as many of the cases, even fatal ones, always remain in this class, and as there are nearly always certain manifestations in addition to the positive one of the presence of amebas, it seems better to give latency a separate place in the clinical classification; and, furthermore, the most useful results will be secured by making such divisions rather sharp and by confining the incubation period in all classes of the disease to the unknown time between the infection and the appearance of amebas in the stools.

Under these circumstances it is readily seen how difficult latency may be to differentiate from what properly may be termed incubation. This becomes all the more difficult when we remember that amebas may possibly be found transiently in the normal intestine and that there are at present no practical means of differentiating between species of amebas. It is clear, therefore, that by basing treatment on the method of diagnosis recommended, unnecessary therapeutics may occasionally be instituted.

Cases of this latent class are not infrequent in Manila and are becoming more and more recognized, as we learn more of the character of the infection, and $I$ do not believe that giving them a place in a purely clinical classification can be criticized by those who have harl experience with the disease in the tropics. They are certainly of very great importance and deserve the most careful consideration, for the life of the patient often depends as much on the diagnosis and treatment here as it does in some of those clinically more active infections. Some of these patients, as has been noted, never show clinical manifestations during life, and in some others, when such symptoms do develop, the time for successful therapeutics may have passed.

The course and outcome, as in some other types, varies greatly. Usually, after a period ranging from a few weeks to many months, more active symptoms develop and in gencral the patient assumes the clinical type of a more or less severe dysentery. This change may occur gradually or very suddenly, and in the latter instance, unless the patient has been under very close observation, we may be misled into believing it to be one of primary acute amebic dysentery. On the other hand, some of these cases go on to recovery or death. without ever showing active diarrhea.

The symptoms during latency may be entirely absent subjectively and objectively for considerable periods of time; but usually conditions develop, which, by the aid

1. Dock, in 1891. reported extensive amebic nlceration in the 1. 1ock, in 1891. reported extensive atery and who had passed cecum of a man who had not had dysentery and who had is a , and Laflenr, in 1897. called attention to the fact that an amebic process may be latent, the stools belng well formed and no amebas bein found in the smal! arherent flakes of mucus, and that in thes cases the diserse is often not suspected until abscess of the liver calls attentinn to it. Ihese observations have leen confirmed by osler; Rogers and many other writers. 
of postmortem findings, we have come to recognize as indicating the nature of the process. As has been stated in previous publications, these cases are essentially those in which the lesions are in the cecum and upper colon. Careful stool examinations, obtained after a hydrogogue cathartic, often show mucus mixed with old discolored blood and other tissue elements, indicating both the location, and with their associated amebas, the nature of the infection. Rather indefinite, dull, aching abdominal pains are frequent and are often attributed by the patient to "taking cold," because they are first noticed during the night or early in the morning, and afterward are usually most active at these times. There may also be some "indigestion," lassitude, headache, a coated tongue, foul breath, etc. Loss of appetite may be present, and the patient often notices slight loss of weight, and, if a woman, usually complains of loss of color and a yellow skin. Physical examinations will usually secure additional data. Deep palpation discloses tenderness along the colon, most often over the cecum, and if the duration is great and the patient not too fat, a thickened intestine may be made out.

Examples of this class of cases, as stated above, have been reported by several writers, and I have called particular attention to them in previous publications. Two additional examples from many that might be given are briefly as follows:

CASE 1.-A young married woman, previously in good health, came to the Philippines in 1903 . About three months later she consulted me, complaining of general lassitude, dull pains in the back of the head and neck, coated torgue and bad breath.

Treatment.- She was given calomel and soda in broken doses, followed by a Seidlitz power the following morning, when examination of the stool slowed amebas fairly numerous and of good size. She was placed on a bitter tonic of iron, quinm and strychnin. For the next three months there was little rhange in the general health and the bowels continued regular. Amebas were again denınstrated in the stools and this time were mixed with mucus, showing streaks of old discolored blood.

Course of Diserse.-I)uring the next month she complained of dull abdominal soreness, which on pressure was more marked in the region of the cecum. "Indigestion" was complained of, anemia was noticeable, and she had lost five pounds in weight: but the bowels were still regular and apparently normal. At this time she consented to take enemas, but after about a week's time she became dissatisfied and passed to the care of another physician, on whose recommendation she spent three months in Japan. While in that country her symptoms of in. digestion were less noticeable and headaches were absent, and she returned feeling in hetter health and spirits. Shortly after her return to Manila, however, there was a recurrence of the symptoms before complained of, and in a more pronounced form; in addition flatulence became annoying; but there was still no diarrhea. Stool examinations after a hrdragogue cathartic showed numerous amebas, and considerable mucus with some blood. Her symptoms. as usual, were relieved temporarily by the cathartic. About this time she had had a moderate diarrhea, which lasted for a few days and was followed by constipation. with severe pains in the right iliac region. Another attack of diarrhea came within a week and dysenteric feces began to be voided. Typical acute dysentery developed, and death occurred within ten days after the acute onset and nearly one year from the time when amebas were first found in her stools.

Autopsy.-At necropsy an old adranced amebic infection of the cecum and upper colon. with most extensive nlceration and chronic fibrinous adhesions were found. More recent amebic lesions were scattered throughout the rest of the colon. and an exquisite acnte diphtheritic dysentery was engrafted on the older process.

CASE 2.-A Filipino prisoner in Bilibid prison showed amebas in his stools on repeated examinations for more than four months. Sometimes after administration of salts blool cells were present, and the mucus was sometimes stained with dark, partly decomposed blood. He was apparently a perfectly healthy man, and had no diarrhea or dysentery.

Lutopsy.-At necropsy, following death from intercurrent lobar pneumonia, the cecum, and ascending and transverse colon showed amebic ulceration, which was quite advanced about the hepatic flexure.

In addition to latency, the symptoms of this infection may be completely masked, and mistakes in diagnosis are, no doubt, frequent when the disease is endemic.

The clinical manifestations of several diseases may mask those of a latent or mild amebic infection. The scope of this paper will not allow a full discussion of these, and the subject will be treated more thoroughly in a paper soon to appear on the complications and sequelæ of amebic infections. Perhaps the most frequent of these conditions, and those which are also likely to lead to mistakes, are chronic constipation and gastritis or appendicitis. The latter of these has already been discussed.2 Gastric symptoms of more or less severity are particularly prevalent in the tropics, both with and without amebic infections of the colon; and for this reason, particularly when severe, often completely obscure the less active disease when present. ${ }^{3}$

Numerous examples might be cited, showing the variety and prevalence of such conditions; but my object here is to call particular attention to it, without leaving the impression that every case of stomach trouble in the tropics masks an amebic infection of the colon.

Constipation is a very prevalent condition in the tropies, as it is in the United States, particularly among women; and, as might be inferred, may frequently mask amebic infection in the early stages, and in the latent and less active forms until irreparable damage may have been done to the colon.

I have under my care now a woman who has for years been a chronic sufferer from constipation. About five months ago she began to lose weight and other symptoms developed, suggesting probable amebiasis, which was confirmed by microscopic examination of the feces. During this time, the constipation had persisted, notwithstanding that blood and mucus were obtained with every specimen secured by salts, and diarrhea did not develop until about two weeks ago. Dysenteric stools quickly followed, and treatment, which is still being, given, was instituted.

Such cases as this and those previously described are of frequent occurrence in practice in Manila and support the conclusion which I have already expressed, namely, that the precence of amebas in the stools should always be considered diagnostic, at least in so far as treatment is concerned. The fact that one occasionally sees a case similar to those mentioned above, in which clinical dysentery never appears, the patient never feels ill, and amehas eventually permanently disappear from the stools, is not a sufficiently strong argument against

2. Bull, 18, Bureall of Governnment Laboratorles THE Totrnal A. M. A., April 8, 1905, p. 1098

3. I now have in mind such a case in a very prominent man in Manila. He had for years been a sufferer from chronic gastritis, and after a few months' residence in the Phllippine Islands the symptoms became more aggravated, and just as previously, he had perlodic outbreaks of diarrhea, only that with the increase in the stomach symptoms, the diarrhea became much worse. At the end of six months he was confined to his bed, unNorse. At the end of six months he was confined to his bed, un-
able to retain food, and reduced almost to a skeleton, and the bowel evacuations had become drsenteric. An examination of the feces showed numerous amphas with blond and mucus. Under careful treatment, directed particularly to the ameblc infection. he slowly Improved and was eventually restored to his nsua. health. 
the conclusion given, until such time as definite data indicating. the final outcome are available early in the infection.

Mild and Moderately Severe Cases.-These form by far the great majority of those seen in Manila at the present time. Formerly they occupied about the same place as that occupied now by latent ones, i. e., they were treated as simple diarrheas from other causes, and of ten the true nature of the infection was not recognized until the development of bloody mucus discharges, or more often the pathologic report called attention to it.

The symptomatology of this class of cases, as well as that of the more severe cases, is so well understood and has been so often described that I will condense that part of the paper into calling particular attention to the conclusion which we have come to in our work in Manila, that diphtheritis and other acute pathologic processes seen at postmortem in this disease are the result of other etiologic agents and are not a part of the true amebic infection.

The larger number of these cases develop from the latent ones already described, just as the majority of the more severe ones usually arise from this type. It is impossible to say just what proportion of them develop as such primarily or follow a more or less definite latent period; clinically, the time of onset is usually dated from the appearance of diarrhea. There may be prodromal manifestations before the onset of diarrhea or dysentery in cases in which amebas may not be found at the time, but here the prodromes are very like the manifestations of the latent type, viz., indefinite abdominal pain, generally attributed by the patient to "taking cold" and explained by not a few as being caused by sleeping without an abdominal band on certain cool nights; tenderness on palpation along a part or all of the colon, "indigestion," headaches, usually of a dull cerebral type, a general feeling of depression, ill health and irritability of temper, and sometimes melancholic tendencies, with anemia and loss of weight.

In the majority of properly treated patients the disease clinically rarely passes from diarrhea, but sometimes here as well as in the larger number of untreated ones diarrhea is only preliminary to a more violent elinical picture. Many cases, however, even without treatment. never become dysenteric in the general acceptation of the term.

The course in uncomplicated cases is extremely chronic and the outcome rarely recovery, being most commonly the development of "sprue" or chronic gactroenteritis giving other clinical pictures; and the most frequent termination is death from intercurrent disease or complications. I am still in correspondence with a number of old Manila patients, now in the United States, in which the cases are of from four to six or more years' duration, and in which symptoms are still very much the same as when the patients left Manila.

Following a gradual onset from a period of known latency, the diarrhea is usually intermittent and more marked in the mornings, consisting of two, three or four soft, semi-fluid stools, without mucus or blood and passed without pain. This condition may last from one to several days, and is usually followed by a tendency to constipation. Succeeding outbreaks usually become more severe and may last for days, weeks or months, until the appearance of blood or mucus causes the patient to realize that he has dysentery, and it is at this stage that he most often appears for treatment. When the onset is more sudden, some blood and mucus are frequently noticed in the stools from the first; there may be some tenesmus and symptoms may continue for a few days, to be followed, as in the first case, by a period of constipation. The subsequent course of the disease in the two cases may not be different, but usually the more acute the onset the more rapid development of more severe symptoms. It is certain that in not a few of these the sudden outbreak is not due to amebas, but to other causes. There are frequently the same extrinsic causes for these outbreaks as when they occur in subjects free from amebas, which is, of course, of frequent occurrence in the tropics, and, in addition to this, careful inquiry will often reveal that there were significant manifestations before the onset in the amebic cases, and it may even be observed when amebas were known to be present for some time prior to the outbreak.

Severe Cases.-The clinical aspects of this type of the disease are the best understood and carefully described, and need but a brief summary here. As is true of the class of cases just discussed, in by far the greater number of cases it develops from a previously existing latent or milder type.

To this class belong also the diphtheritic and gangrenous cases, which are always severe and are undoubtedly due to a concomitant or secondary infection with some other agent, which is also the cause of severe forms of other types.

The onset here, whether occurring in an apparently healthy subject or following an existing milder type, is nsually quite sudden and is characterized by the phenomenon of an acute dysentery from other causes. There are frequent mucus bloody passages, with tenesmus, colic, thirst and perhaps some fever.

In this severe form. whether apparently primary or secondary to one of the milder types, the course is usually much shorter and death is frequent from toxemia, perforation of an ulcer or from exhaustion of the patient. There are cases in which postmortem examination may show excellent nutrition and a rotten intestine, with either extensive gangrene or diphtheritis. Even in these. however. not infrequently the severe symptoms subside under treatment. and the cace mav contintue as a more moderate one, or may be even mild in its svmptoms. thus exemnlifying the previous statement that the rlinical tymes designated may frequently change from one to another even in the same patient.

Infection in Children.-Particular attention has been called to the disease in children by several writers. ${ }^{4}$

I have had twenty-one cases in children between the ages of 6 months and 10 years in private practice in the Philippine Islands, and one necropsy in a girl $31 / 2$ years old. When we consider the increased danger of infection which is present for children in the tropics, wo must conclude that they present an increased natural immunity, a fact which is still further borne out by a study of cases in which infection does occur, for the discase is usually of a very mild type and is very amenable to treatment. In only two of my cases (in addi-

4. Amberg, in 1901, carefully reported five cases from the Johns Hopkins Ifnspital, and reviewed the literature on the subject. Harris reported thirty-five cases, four of them in children under 10 years of age. Strong found amebas in the tuberculons ulcers of a 3-year-old child; Siaughter in liver abscesses of a 17-year-old boy; Kartulis in children of all ages except infancy: Pfeiffer in the stools of several children; Lamb in a 2-yearold child: Lutz in the stools of a little glrl; Sorisino in the intestinal mincis of a cbild; Cahen in a girl 4 years old: Gneftos in the liver abscess of a 6-year-old girl. Oddo (1897) reported twelve cases of liver abscess following dysentery in children between the ages of 2 and 13 . 
tion to one death) was the disease what could be called moderately severe from its clinical manifestations. 'The symptoms, in general, conform to the milder types in adults, and recovery is almost certain under proper treatment. I have seen children in whom there was undoubted active infection recover without treatment.

The aged, as in the case of children, seem to manifest a decided natural immunity; but, when once established, the disease in them is usually of more serious import than even in young adults. The symptoms are commonly of a severer nature, the course is more rapid, and the mortality higher, generally, as in other patients, due to complications or to intercurrent disease.

One thing particularly noticeable both in children and in the aged, as well as in natives of the Philippine Islands, is the great relative infrequency of liver abscess. I have not seen a case of liver abscess in more than one thousand clinical cases and one hundred autopsies of natives of the Philippine Islands.

Analysis of Symptoms.-All varieties of facial aspect are seen, from a healthy one in some of the rapidly fatal cases to the more emaciated, anemic, yellow and even cachectic of some in the old long-standing ones. Usually for a long time the patient does not appear to be ill, and I have seen patients with the disease of more than two years' duration who had lost no time from the daily occupation.

In the early part of the disease the skin rarely shows any noticeable change, but in the old emaciated cases there is a general waste and a scrawny, dull, goose-flesh skin, often of a muddy color or even jaundiced. In this class of cases there is frequently an odor which is quite disagreeable and which is as characteristic as for any of the diseases in which its diagnostic value is emphasized. Perspiration is usually not very active, but cases are occasionally seen in which the night sweats equal those of tuberculosis. Edema, particularly of the feet, ankles and less frequently at the hands, and the face about the eyes, is often present, but is not necessarily an indication of Bright's disease. Albuminuria and casts may be present at times when these edemas are noticed; and involvement of the kidneys is frequently observed postmortem, though in the majority of the cases terminating in recovery the proper functioning of the kidneys is restored, and there is no further trouble from this source. Bed sores are rarely seen, except in the most chronic types of old emaciated, anemic patients, shortly before death. Boils are frequent in the tropics during convalescence from any wasting disease, and in amebiasis they are not exceptional. Of rashes, urticaria is of quite frequent occurrence and often annoying in its persistence. Quinin rashes, from absorption of this drug, are the most frequent and troublesome. often requiring a suspension or change of treatment. Enlargement of the superficial lymphatics without pain is common, particularly among natives; but this is so frequent an occurrence in health and other discases that diagnostic importance can not be attached to it.

Digestive System: The organs of digestion bear the brunt of this disease, and it is here that diagnostic simptoms are most frequently observed. The appetite is most generallv good, particularly so in the latent and mild cases during the early part of the disease. Tuter catarrbal conditions of the upper intestine, stomach and rren esophagus are followed by variations in the appetite. due to such alterations. In the early disease, likewise, hut little or no discomfort is felt from satisfving a normal desire for food, but later such action is often followed by an increased diarrhea and by a further disturbance of the already disordered upper digestive tract.

The tongue is in no sense a valuable interpreter of the conditions at the seat of the amebic lesions. It may be clean or coated with furs of various colors and types. It may be large or swollen, showing the marks of the teeth along its edges, or it may be red and pointed. In very old chronic cases, in which the clinical picture is that of sprue, the tongue is one of the valuable indicators and here often shows small ulcers along its sides and under the tip. Glossitis, with superficial ulcers and hyperemia of the mucous membranes (sprue), is not uncommon, and when present causes a dryness and burning sensation, which is very annoying. In the same class of cases, too, the frequent lesions of the esophagus cause a burning pain along this viscus, which is aggravated by acids or solid food. Thirst is usually increased and often markedly so when the clinical symptoms are quite active, due, no doubt, to the loss of body fluids through the ulcerated bowel.

Symptoms referable to the stomach depend, for the most part, on various stages of catarrh of this organ and do not differ from symptoms of similar conditions due to other causes. In the early part of the disease, the stomach most frequently remains in good condition, but in the later stages, and sometimes quite early, its symptoms may be very annoying. Nausea is frequent, but vomiting rare at any stage. Both these conditions are aggravated and frequently are direct sequences to treatment by enemas. Symptoms of hyperacidity, with beefy-red tongue and epigastric pain (heart-burn), are encountered from time to time in all classes of cases; but a fermentative condition, with gas, a large, coated, flabby tongue, nausea and loss of appetite, are more common conditions.

The small intestine may be normal, but sometimes in the more chronic cases it shows a general catarrha? condition, which manifests itself by the usual symptoms of enteritis of other etiology. True amebic ulceration occasionally extends for from 2 to $10 \mathrm{~cm}$. into the ileum. and in one case a perforation of an ulcer above the valve occurred, and the symptoms brought about by it closely resembled those seen in severe infection of the cecum.

The Large Intestine and Feces: The bloody-flux interpretation of the word dysentery must be abandoned in this disease, or, perhaps, a better solution would be to change our nomenclature so as to avoid calling it dysentery at all. It is true that diarrheic, or even dysenteric, stools are present at some time during the course of the disease in the majority of cases which proceed to a fatal termination; but even here this is not always so. and true dysenteric stools are not the rule in patients in whom treatment has been instituted early and properly administered.

There are numerous examples in literature of patients who have died of the disease in whom during life there was slight or no clinical dysentery. Such cases have heen reported by Councilman and Iafleur, Osler, Dock, Strong and Musgrave and many others; and we (Mr. Clegg) have emphasized it in a recent paper.

In this paper I have already cited cases, and to them could be added at the present time a considerable numher in which there was no diarrhea or dysentery at anv period during the course of the disease, and vet death occurred from perforation of an ulcer or from intercmrrent disease. Further, within the past year, in addition to a case already mentioned, I have nerformed the necropsy on the body of a patient who had been treated 
for more than six months for constipation, in whom advanced amebic ulceration of the cecum and ascending colon was found after death, resulting from perforation of a liver abscess. Such cases, of course, are not the rule, but they are sufficiently numerous to be of importance and are emphasized particularly for the purpose of demonstrating that, as in the case of many other infections, experience broadens our conception of the clinical picture.

With this data, I am prepared to state that in this disease there may be any stage between constipation and severe clinical dysentery, or alternations between these two conditions may be present throughout the course of the disease; and it is in this variation that we secure data for the arbitrary clinical division of the cases.

From what has been said it is seen that this clinical division is not necessarily borne out by the pathologic picture, and, therefore, it must not be inferred that the disease is of necessity mild because of the absence of a severe diarrhea.

In the great majority of cases, after a more or less prolonged incubation or period of latency, alternating periods of diarrhea and constipation develop, and usually the diarrhea becomes more severe with each return and persists longer, the constipation becoming less marked until finally formed feces are no longer passed. The diarrhea is usually more pronounced in the morning and after meals. In long-standing cases, the patient complains that the food passes through unchanged as soon as eaten.

There is nothing characteristic in the macroscopic appearance of the feces. Their consistency, amount, color, etc., may vary between the widest limits. In the early stage of the disease they are frequently formed and otherwise normal, and the surface may or may not show coatings of mucus sometimes streaked with blood. The morning specimens are usually the first to have a diarrheic appearance and are often copious and fermenting. When the infection is more advanced, the feces may take on the appearance of those due to chronic catarrhfluid, with mucus and particles of undigested food. On the other hand, frequent large, light gray fluid or grannlar, foul-smelling evacuations, with mucus, and with or without fresh or old blood, and sometimes masses of tissue and occasionally casts of the mucosa, may persict for weeks or months. Again, particularly when the infection is low in the colon and rectum and there is some severe secondary infection, the stools may resemble those of acute dysentery in character and symptoms produced. The odor of the feces in many cases is particularly offensive and all but characteristic, so much so that diagnostic importance may be attached to it. Thn next most important point of diagnostic value obtain from a macroscopic examination is the indication of the location of the infection by the character of the blood. when such is present.

Amebic infections can be diagnosed with certainty only by microscopic examination of the feces or other material, and by this method also other valuable data may be obtained.

The best method of securing a specimen and the manner of procedure for microscopic examination have been described in Bulletin No. 18, Bureau of Government Taboratories, and some additional points are mentioned under the heading of diagnosis in this paper.

'The presence of motile amebas should be considered diagnostic, at least in the tropics. The difference in size and numbers. the presence or absence of enclosed blood cells, and other described points of differentiation, I believe to be fallacious, as pointed out in a previous publication.

Many other parasites and substances of more or less importance are often found associated with amebas. Among animal parasites are the Trichomonidce, Cercomonida, Megastoma entericum, Embryo strongyloides, ova of uncinaria, Trichuris, Tonia, Oxyuris, and others, either singly or in various combinations. At least some of these have a part in the production of the symptoms and must be reckoned with in treatment. Of other substances present may be mentioned leucocytes, red blood cells, pus, epithelial and other cellular elements. Various crystals are often present, but with one or two exceptions are of no diagnostic importance. Many other substances may be found, but as they have been so repeatedly discussed by others and are of such slight importance to the subject in hand they will be omitted.

Circulatory System: The circulatory system in this disease shows essentially the changes of secondary anemia. The pulse is usually of good quality, except in the later stages or in the presence of complications, when it takes on a type due to such involvements. Early in this disease the blood shows little or no change, the red cells being normal in numbers and free from abnormal elements, the leucocyte count is normal, the relative proportion of the cells is not disturbed, and the hemoglobin estimate is also normal. As an uncomplicated case progresses, the red cells begin to show changes due to anemia, and in the later stages the irregularity in their size and shape may be quite marked, and the count may show great reduction, notwithstanding the loss of fluid from diarrhea. The leucocytes under like conditions show some disturbances in relation of varieties, usually an increase in polynuclears and eosinophiles, but these changes are never stich as to be of diagnostic value. Hemoglobin decreases with a reduction in the number of red blood cells. The spleen is not enlarged. except in some severe cases complicated by or associated with other infections.

Temperature: Fever is most often absent throughout the course of the uncomplicated disease. It may be prescnt in a moderate degree, when it is usually of an intermittent type, highest in the afternoons. In acute exacerbations from any cause, and when there is an intense secondary involvement, particularly diphtheritis, it may be an important factor. Only recently I was for some weeks very much puzzled by an intermittent temperature, reaching its maximum of from 38 to $39^{\circ} \mathrm{C}$. about 10 o'clock a. $m$. dajly, in an amebic patient, until other symptoms proved the presence of an intercurrent syphilis. It is frequently found, but by no means constantly so, in liver abscesses. Here, if the abscess is also the seat of bacteria in considerable numbers, the septic temperature may closely resemble that of a malarial infection, endocarditis or almost anything else, of either the intermittent or the remittent type. On the other hand, one occasionally finds a large liver abscess withnut fever at any time. As the disease becomes more advanced, it is quite common for patients to exhibit subnormal temperatures. narticularly during the forenoons. for days, wecks or months in succession.

Nervous System: This probably does not suffer much as a direct consequence of amebic infections, but of this I am not at all sure. There are many cases of neuritis, neuralgia, etc.. which are so closely connected with the disease that until we are more fully accuainted with the exact method of the action of amebas in other parts of 
the body, our opinion can only be based on supposition.

Pain: The subject of pain in general, however, may be conveniently discussed here. Its variety and intensity in this affection is very great. It is partly a direct consequence of lesions and partly the result of more remote and sometimes unexplainable causes.

Tenesmus is more often an indication of complications or severe secondary involvement than of amebic infection. It is never present in the latent forms and is usually absent or very slight in those of moderate severity; but during acute exacerbations of either of these, and particularly when diphtheritis or other secondary infection, including that of $B$. dysenterice Shiga, is present, it may be very severe. It is much less severe or more likely absent when the lesions of whatever type are in the cecum or upper part of the colon.

Colicky pains are not infrequently seen, and even severe acute intestinal colic sometimes supervenes, especially when there is marked catarrh of the small intestine.

Dull, aching, somewhat indefinite abdominal pain is one of the most frequent prodromal symptoms, and quite frequently it is persistent during the disease. Sometimes it is so severe and constant that rest is im. possible for days or weeks at a time. Though most usually complained of as being of maximum intensity along the course of the colon, as general careful palpation will show, not unusually it is found only in the region of the cecum and is sometimes complained of in the muscles of the back. Such pain may be due to the processes going on in the bowel, and, again, as demontrated by postmortem examination, it may be the only indication during life of the most extensive serous inflammations and adhesions. These pains are often most active in the night, even in the mildest cases of infection, and may interfere seriously with the patient's rest.

Pains described by patients as "heart burn in the abdomen" may be general or more frequently local. When active lesions are low in the sigmoid and rectum. these and what are described as burning pains are frequent. The latter may be intense about the rectum, and mav sometimes extend down the backs of the thighs and even to the calves of the legs. Old sciaticas are often "fired up" under these circumstances, and the beginning of sciatica is associated with such cases often enough to be suggestive.

Pains simulating those in appendicitis have been more fully discussed in Part 2 of Bulletin No. 18, Bureau of Government Taboratories, and in the Jodrnal A. M. A.. April 8, 1904. They are probably the most important with which we have to deal, because their true interpretation is so vital to the patient and because thev are of such general occurrence in all varieties of amebic infection, from the latent to the gangrenous, with or without the presence of amebic or other forms of appendicitis.

Neuralgias, mralgias and arthralgias are met with ton frequently to allow them always to be considered accirental associations. Persistent, dull headaches. particularly of the back of the head and neck, are also not uncommon. The genitourinary and respiratory svstems and the organs of special sense rarely contain lesions which produce symptoms of any importance in the uncomplicated disease. The same is true of the joints and the osseous system. though complications may inrnlve any of these structures.

\section{DIAGNOSIS.}

There are no classical symptoms in the disease. and hence an absolute diagnosis can be made only by microscopic examination of the feces.

In remote areas where the infection is endemic ani where microscopic facilities are not available, one woulıl be justified in making a diagnosis for purposes of treatment from clinical manifestations alone, but where laboratories are accessible this should never be done.

If one remembers the multiform clinical pictures which have already been discussed and watches the case for some time, a diagnosis of amebic infection may reasonably be inferred, but it. must be borne in mind that the clinical picture does not in general differ materially from that often seen in diseases with an cntirely different etiology, and, further, that there is not a single symptom or group of symptoms which is confined to this disease alone.

The following are the most important clinical manifestations in a question of diagnosis :

1. The bowel evacuations, particularly their odor, and the presence or absence of blood. Their consistency. quantity, frequency and the presence or absence of mucus, are much less important.

2. Abdominal soreness, which is increased on pressure and extends particularly along the colon, is most common and, taken singly, is one of the most valuable symptoms. Its diagnostic importance is greatest when of maximum intensity over the cecum and ascending colon.

3. So-called "indigestion" headache, general lassitude, with nausea or pain below the stomach after eating, etc., is quite common, but is also prevalent at other times, so that but little importance must be attached to it alone.

4. Ioss of weight, especially in the presence of a good appetite, is quite important and is the best guide to the progress being made by the infection.

As already stated, neither one nor all of these symptoms taken together are sufficient for an absolute diagnosis; but when taken together in cases where carefu] palpation reveals a thickened, tender colon in places where it may be felt, they make the nearest approach to a sure diagnosis possible without microscopic examination of the feces.

'The question as to whether the presence of amebas in the feces is always absolutely diagnostic of an infection of the colon has already been discussed. It may be that such is not always the case, but I believe that it is so nearly so that such an occurrence, at least in the tropics, should be considered diagnostic, at any rate for purposes of treatment. Such a conclusion is all the more justifiable when we consider the great certainty of good results in treatment instituted early, the long incubation period or latency which severe cases may show, the inability ever to establish a more certain diagnosis in those cases of light infection which terminate in recorery and, finally, above all, the great reduction of the danger of liver abscesses by instituting early treatment. It will be remembered that, according to statistics from many places, including Manila, over 20 per cent. of untreated patients or those not treated by enemas have dcveloped liver abscesses, and that in a verv largo numbrr of patients treated by my colleague and myself in private practice during the last few years, along lines laid down in Bulletin No. 18, there have not been more than two cases of liver abscess which developed after treatment was instituted. Inasmuch, then, as a correct diagnosis can be made only bw finding amebas in the intoctinal contents, and as their presence here. at least for 
purposes of treatment, are to be considered diagnostic of infection, regardless of clinical symptoms, the best method of determining their presence or absence should be part of our subject.

This is not always an easy matter. When there is active clinical dysentery, a microscopic examination of one of the passages will usually reveal amebas, but even here single or even several examinations will often yield negative results. The specimen for examination should, when practicable, be one obtained by some hydragogue cathartic, because the infected area frequently includes only a portion of the colon, and by this means the specimen is more certain to contain feces from the entire track.

For the same reasons, the method of extracting a specimen through a speculum can be of maximum value only where the lesions are in the lower bowel. For obvious reasons castor oil is not a satisfactory cathartic for this purpose, and specimens obtained by enemas are likewise unsatisfactory.

The specimen should be as fresh as possible when examined, for, while amebas will usually remain motile for several hours and sometimes for days, in many instances they lose their motility in a very short time. In Manila, a warm stage will never be found necessary, and a diagnosis had best not be made from any but motile organisms.

Usually no difficulty will be experienced in differentiating amebiasis from other diseases, but when other troubles exist as complications or associated diseases, which is of very frequent occurrence, the solution is often not so simple. Suffice it to say here that in practically every instance in which such complieations or associations do exist they are rarely of a nature which offers contraindication to the institution of the usual treatment of amebiasis, and, therefore, whether or not the nature of the complicating trouble is determined, treatment of the amebic infection should be prosecuted. PROGNOSIs.

The prognosis in this infection should take several points into consideration, and the evidence in each individual case should be carefully weighed before an expression of opinion is justifiable.

Fortunately, in Manila, owing to the good results of treatment, the physician is rarely called on to say very much; but in the more prolonged and persistent cases prognosis is eagerly sought by the patient and his friends. In general, under proper treatment recovery is the rule in young, well-nourished adults, in whom the disease is not of too long duration.

The principal determining factors in giving such prognosis are the manner of treatment, age, nationality, general condition of the patient and duration of the disease at the time treatment is instituted, reaction to treatment, the presence of complications and associated diseases, and, finally, the location of the amebic lesions. ${ }^{5}$

It must be remembered that in a certain percentage of cases, particularly in children and natives, the patients recover from the disease without any treatment whatever. On the other hand, one occasionally sees a natient in whom the disease is progressive from the first, and death is not apparently delayed by any form of treatment.

The disease is generally milder in children and in

5. In my last $10 n$ completed cases treated in private practice including all types and stages of the disease, 96 patients bave nermancntly recovered without leaving the Phllippine Islands. There has been one death and three have returned to the United states. natives of the tropics, and its course is more often shorter and its mortality higher among the aged. Alcoholics apparently are less frequently infected, but when once the disease is established the gravity of the prognosis is increased. Previous good health and good general physical condition are favorable factors. The shorter the duration of the disease at the time treatment is instituted and the greater the tolerance for enemas the more favorable the prognosis.

The presence of complications or associated troubles, such as liver abscess, severe hemorrhoids, fistula or fissure in ano, and many others less frequent, materially decrease the chances of ultimate recovery. Probably most important of all, however, is the Iocation of the lesions. As a rule the higher up the lesions, the greater the mortality and the less active the clinical dysentery. Severe infections of the cecum, unless treated early and carefully, are always serious.

\section{CONCLUSION.}

In conclusion, I wish to emphasize the fact that intestinal amebiasis (amebic dysentery) manifests itself in a much broader and more comprehensive clinical picture than is generally allotted to it.

Waiting for bloody mucus stools to appear before making a diagnosis and instituting treatment is responsible for a large percentage of the present mortality from the disease in Manila. Such stools sometimes appear early in the disease, more usually after considerable damage has been done, and occasionally are never seen before a fatal termination or recovery.

Suppose, for example, that by treating every patient in whom motile amebas are found, as recommended in this paper, we do occasionally treat a person who would have recovered without treatment, or possibly would never have had an active lesion, are we not justified, when we consider that by such procedure established early, without waiting for clinical dysentery, we increase many fold the chances of recovery of all patients?

\section{DISCUSSION.}

Dr. GeoRge Dock, Ann Arbor, Mich., said in regard to the importance of distinguishing the latent, that he was fortunate enough to see a latent, mild or variable case very long ago, and he has already called attention to it. Briefly, the history of the case is as follows: The patient was a man who, for several months, had no loose stools at all and no diarrhea, and was absolutely free from any symptoms ordinarily referred to as dysenteric, yet he developed a liver abscess which was operated on and proved to be amebic. The patient died a few days later, and it was shown that not only were there lesions in the cecum, but also in the upper part of the large intestine, as well as in the liver. The stools Dr. Dock examined and found no amebas or other evidences of the disease. If the patient had been under his observation a longer time the diagnosis might have been made prior to death, especially if saline cathartics, as Carlsbad salts, had been given to facilitate the examination of the stools. In diagnosis, the most important thing is the proper examination of the stools, and this has been much neglected because it has been supposed to be so difficult. By giving Carlsbad salts, stools can be secured whenever wanted, and there is really no difficulty in finding the amebas, even in cool media or in cool rooms. As an important and practical aid in this examination of the stools, they should be examined, not in deep vessels, but in flat vessels, the broad low granite dishes answering the purpose very well. A certain amount of practice is necessary in order to be sure always that what is seen are really amebas. Dr. Dock likes the modification of Jenner's stain, which he believes to be as good as the specific stains. His experience in the South shows that it is comparatively easy to treat this disease if it is seen at the beginning. Cathartics should be vigorously given, and irrigations of any kind are useful, his preference 
being for strong saline solutions. In the chronic cases the treatment is more difficult. These latent cases are the ones which are likely to be seen in this country. At the Saratoga session, Dr. Dock was able to report such a case, and within the last year he has seen another example which occurred in a man who had never been outside of the United States at all, and yet he had a severe infection with Amaba coli. The greatest care possible is demanded in the treatment of the patient. It is very necessary that constipation should be avoided. Instructions regarding the diet may vary greatly. He has seen beneficial effects from the use of ipecac used after the manner of Strong, covering it with salol. About one year ago he saw an interesting case of amebic infection from the Philippine Islands. The patient had amebic dysentery, as well as uncinariasis and the Tricocephalus dispar. He was treated for uncinariasis with thymol, and the amebic signs then disappeared as well. Although this is spoken of as a tropical dísease, it may occur in other parts of the country. Though the clinical picture varies greatly, the diagnosis can be made, and the treatment is becoming more and more satisfactory.

DR. H. R. LEMEN, Alton, Ill., stated that he has had two years' experience in the Philippines, and made careful examinations of 532 males and 53 females who were taken there as prisoners without any apparent evidences of the disease whatever, and he found 91 males and 11 females with amebas. Among 50 soldiers there were found 10 cases of liver abscess.

Dr. Stanlex Black, Los Angeles, Cal,, asked Dr. Musgrave for the points in differential diagnosis between Amaba coli and other amebas which exist in the stools. Dr. Black has seen a number of cases in which amebas were present in the stools, but in which there were no symptoms of dysentery, such as one expects to find when the Amobba coli is present. $\mathrm{He}$ also asked if Dr. Musgrave considers the presence of red corpuscles diagnostic of the $A m c b a$ coli and if the pathogenicity for cats is of importance in diagnosis. In Dr. Black's opinion the material for examination can best be obtained by the introduction of a rectal tube. The mucus so obtained often contains many amebas.

Dr. F. C. Shatruck, Boston, stated that he has seen one case of amebic dysentery in a man who had not been out of New England. This simply corroborates what has already been stated, that the disease is not necessarily one of the tropics.

Dr. Cuavde A. Smith, Atlanta, Ga., said that physicians meet some cases of amebiasis in the South, but of course not anything like the number found in Manila. As an illustration of the fact that some patients appear to recover or even recover without treatment, Dr. Smith said that five years ago, at the request of Dr. $H$. F. Harris, he made a postmortem examination of a man who ten years previously presented elinical symptoms of a severe type of the disease. $\mathrm{He}$ removed the colon, but there was no evidence of any uIceration, nor any macroscopic signs of previous ulceration. This also showed that the symptoms of the patient are not necessarily an index of the extent of the lesions. He recalled one or two autopsies in which he found extensive ulcerations throughout the colon, and yet the clinical symptoms did not indicate anything serious. There was one case in a negro man, about 45 years of age, whose muscular development was perfect, presenting no signs of emaciation, and who was not considered to be in serious condition, and yet he died fortyeight hours after admission to the hospital. The colon's en. tire mucous membrane was found to be necrotic, and yet that man had been hard at work until two days before death. He asked if Dr. Musgrave has been able to trace these cases of amebiasis after apparent recovery, and if he has found many relapses.

Dr. W. E. Musgraye, Manila, P. I., said that all the questions and points brought out in the discussion have been carefully gone over in the present paper and in previous publications. (See The Journal A. M. A., April 8, 1905, p. 1098, and Bull. 18, Bureau Government Laboratories, Manila.) In conclusion he emphasized the fact that the symptoms produced by this affection are in no way proportionate to the danger done to the bowel.

\section{AFFICTIONS OF THE THYROID IN CALIFOIRNIA.* \\ HERBERT C. MOFFITT, M.D. SAN FRANCISCO.}

Six years of hospital and private work in San Franeisco have strengthened the conviction that affections of the thyroid, like aneurisms and early arteriosclerosis, are more common here than in many other cities of the United States. With this idea in view, letters were sent during the last months to men in each county of the state asking for information as to the occurrence of goiter, myxedema, sporadic cretinism, and exophthalmic goiter in their districts. My obligations are here expressed to many colleagues who have kindly sent reports. There seems to-day little need for review of reasons in grouping exophthalmic goiter with thyroid affections-the influence of nervous factors can not be denied the possible influence of other internal secretions in etiology is recognized, but the gland plays a chief rôle in symptomatology (even though, as Moebius says, there may be a prethyroid stage of the disease). Despite the vast amount of work of late on the parathyroids by Gley, Edmunds, Welch, Benjamins, Jeandelizo, Moussu, Vassale and Generali, Lusena, MacCallum, Brissaud, Pineles and others, it is not yet possible to say that they color in any way the picture.

The statement of Hirsch that "our information on the endemic occurrence of goiter in North America belongs for the most part to the early years of this century and is very fragmentary" can be modified in light of articles by Richardson, by Adami on goiter in Canada, by Osler on "Sporadic Cretinism in America," by Dock on "Goiter in Michigan." The Medical Sentinel, February, 1904, had an editorial on goiter in the northern Pacific states, and Iately Musgrave of Washington described the great frequency of the condition in the Wenatchie and Puyallup Valleys in animals as well as man. Praslow years ago reported cases of cretinism among Indians near Cape Mendicino, Humboldt County, and among the Spaniards in Southern California. Osler in his article on sporadic cretinism wrote: "Praslow's account of the occurrence of cretins in California $I$ have not seen, but I have letters from several correspondents in that statc who know nothing of its existence at present, while in the State Insane Asylum at Stockton. Dr. Hoisholt tells me there are only two cases." It is interesting to note from reports of Dr. Gross of Fureka and Dr. Delamere of Ferndale that goiter is common in Humboldt County, not far from Cape Mendicino, although accounts of only two cretins are sent from that district. I have seen two cretins among Indians ncar Kelseyville, Lake County. Reports from Southern California do not substantiate the account of cretinism among the Spanish settlers.

\section{GOITER.}

Data concerning goiter must of necessity be unsatisfactory. as slight or even moderate enlargements of the gland are often overlooked; and, as in all statistics, the personal equation of the reporter must be considered. A few weeks since a physician came personally to report the absence of thyroid affections in his district and presented himself a good example of myxedema. The testimony of physicians from counties about San Francisco Bay (Marin, Alameda, Santa Clara, San

* Read in the Section on Practice of Medicine of the American Ifedicai $A$ ssociation, at the Fifty-sixth Annual Session, July, 1905. 